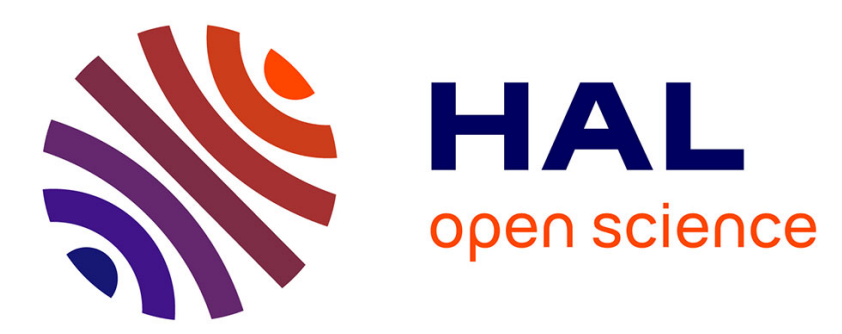

\title{
Different calcium-dependent pathways control fertilisation-triggered glycoside release and the cortical contraction in ascidian eggs
}

Charles C Lambert, Alex Mcdougall, Christian Sardet, Charles. Lambert

\section{To cite this version:}

Charles C Lambert, Alex Mcdougall, Christian Sardet, Charles. Lambert. Different calciumdependent pathways control fertilisation-triggered glycoside release and the cortical contraction in ascidian eggs. Zygote, 1995, 3 (3), pp.251-258. 10.1017/s0967199400002641 . hal-03025664

\section{HAL Id: hal-03025664 https://hal.science/hal-03025664}

Submitted on 16 Dec 2020

HAL is a multi-disciplinary open access archive for the deposit and dissemination of scientific research documents, whether they are published or not. The documents may come from teaching and research institutions in France or abroad, or from public or private research centers.
L'archive ouverte pluridisciplinaire HAL, est destinée au dépôt et à la diffusion de documents scientifiques de niveau recherche, publiés ou non, émanant des établissements d'enseignement et de recherche français ou étrangers, des laboratoires publics ou privés. 


\title{
Different calcium-dependent pathways control fertilisation-triggered glycoside release and the cortical contraction in ascidian eggs
}

\author{
Alex McDougall ${ }^{1}$, Christian Sardet ${ }^{1}$ and Charles C. Lambert ${ }^{1,2,3}$ \\ Station Zoologique, Villefranche-sur-Mer, France, Station Biologique, Roscoff, France, and Biology Department, California \\ State University, Fullerton, USA
}

Date submitted: 16.7.95. Date accepted: 20.7.95.

\section{Summary}

Fertilisation of ascidian eggs induces the rapid release of a cell surface $\mathrm{N}$-acetylglycosaminidase that blocks sperm binding to vitelline coat sperm receptors resulting in a block to polyspermy. Fertilisation also triggers a large contraction of the egg (thus stimulating ooplasmic segregation) that is completed within $5 \mathrm{~min}$ of insemination. In eggs of the ascidian Phallusia mammillata, glycosidase release and cortical contractions are blocked by BAPTA-AM [bis-(o-aminophenoxy)-ethane- $N, N, N^{\prime}, N^{\prime}$-tetraacetic acid, tetra(acetoxymethyl)-ester], a cell-permeant calcium chelator, indicating that both processes are probably dependent on a rise in intracellular calcium levels. Both glycosidase release and the cortical contraction are induced by treatment of the egg with the protein synthesis inhibitor emetine, while only the glycosidase release is induced by isoproterenol, carbachol or acetylcholine. Previous work with ryanodine demonstrated that ryanodine also caused glycosidase release but not the cortical contraction. Inversely, activation by ionomycin in calcium-free sea water causes cortical contractions but not glycosidase release. Thus the two processes can be activated independently. Dextran-coupled $(10 \mathrm{kDa})$ calcium green-1 injected eggs show an increase in intracellular calcium $30-40 \mathrm{~s}$ before the cortical contraction is triggered by fertilisation or ionomycin-induced activation. This confirms previous findings that the cortical contraction is a consequence of the activation calcium wave triggered by the sperm. The extracellular calcium requirement for the glycosidase release suggests that calcium influx may be more important for this phase of egg activation. Thus activation of ascidian eggs appears to involve two independent pathways involving calcium.

Keywords: Ascidian, Calcium, Cortical contraction, Egg, Glycosidase release

\section{Introduction}

Fertilisation of the animal egg results in a rapid increase in the free cytoplasmic calcium $\left(\mathrm{Ca}_{\mathrm{i}}^{2+}\right)$ level. This in turn triggers other events, such as cortical granule discharge and re-initiation of the cell cycle (Nuccitelli, 1991, for review). How the sperm generates

All correspondence to: Alex McDougall, URA 671 CNRS/ Paris VI, Station Zoologique, F-06230 Villefranche-sur-Mer, France. Fax: 33.93.76.37.92.

${ }^{1}$ URA 671 CNRS/Paris VI, Station Zoologique, F-06230

Villefranche-sur-Mer, France.

${ }^{2}$ Station Biologique, Place Georges Teissier, F-29680 Roscoff, France.

${ }^{3}$ Biology Department, California State University, Fullerton, CA 92634-9480, USA. this increase is under intense scrutiny in a wide variety of mainly deuterostome eggs (Whitaker \& Swann, 1993; Berridge, 1993; Galione et al., 1993; Lee et al.,1993; Swann et al., 1994, for reviews). In sea urchin and vertebrate eggs, two major calcium-release channels have been implicated in the release of intracellular calcium: these are the inositol $(1,4,5)$-tris phosphate receptor $\left(\mathrm{InsP}_{3} \mathrm{R}\right)$ and ryanodine receptor (RYR) channels. It is thought that these two proteins can form functional homotetramers across the bilayer of the endoplasmic reticulum (ER). The Ins $P_{3} R$ channel is triggered to open by cytoplasmic increases in the level of Ins $\mathrm{P}_{3}$ and $\mathrm{Ca}_{i}^{2+}$, while the non-skeletal forms of the RYR channel are triggered by cytoplasmic increases in cyclic ADP-ribose and $\mathrm{Ca}_{i}^{2+}$ (see Galione \& White, 
1994, for a recent review). Both receptor channels seem to be modulated positively by cytoplasmic $\left(\mathrm{Ca}^{2+}\right.$ increases, while only the Ins $P_{3} R$ channel is also desensitised by physiological $\mathrm{Ca}^{2+}$ increases: the opening of Ins $P_{3} R$ channels displays a bell-shaped response as the $\mathrm{Ca}^{2+}$ concentration in the cis compartment changes over the nanomolar to low micromolar range (Bezprovanny et al., 1991).

Ascidians are invertebrates like the sea urchin, but they are also members of the phylum Chordata, since they develop through a swimming tadpole stage. Fertilisation of the ascidian egg, which lacks cortical granules, results in a rapid release of $N$-acetylglycosaminidase from the cell surface (Lambert \& Goode, 1992). This results in a block to polyspermy through inhibition of sperm binding to the vitelline coat (Lambert, 1989). This is followed by a cytoskeleton-controlled cortical contraction, re-initiation of the cell-cycle and polar body production (Sardet et al., 1989, for review). The cortical contraction is preceded by an increase in $\mathrm{Ca}_{\mathrm{i}}^{2+}$ levels (Speksnijder et al., 1989, 1990). Since the contraction can occur in $\mathrm{Ca}^{2+}$-free sea water, the $\mathrm{Ca}_{\mathbf{i}}^{2+}$ is likely to be released from internal stores such as the ER: this idea was substantiated by the demonstration that injection of $\operatorname{InsP}_{3}$ can stimulate the calcium release and the cortical contraction (Dale, 1988). In sea urchin eggs, both the Ins $P_{3} R$ and the RYR are probably responsible for the calcium relased at fertilisation (Galione et al., 1993; Lee et al., 1993), while in amphibians only the InsP $\mathrm{P}_{3} \mathrm{R}$ seems to be involved (Nuccitelli et al., 1993). Like sea urchin eggs, ascidian eggs seem to have the RYR, based on evidence that glycosidase release is induced by adding ryanodine to the medium. This, in contrast to the cortical contraction, requires extracellular calcium (Lambert et al., 1994)

In this study, we report on the kinetics of the cortical contraction and glycosidase release based on the observation of egg populations, and we have established that glycosidase release precedes the cortical contractions induced by fertilisation or activation with the calcium ionophore ionomycin. Emetine (a protein synthesis inhibitor) induces glycosidase release, cortical contractions and first polar body production. In contrast, only the glycosidase release is induced by acetylcholine, carbachol, isoproterenol or ryanodine in the absence of cortical contractions. However, like the cortical contraction, glycosidase release is also inhibited by the cell-permeant calcium chelator BAPTA-AM (Lambert et al., 1994). From these observations we conclude that, in the ascidian egg, two calcium-release mechanisms operate at fertilisation: one leads to amoeboid deformation of the eggs, polar body production and is dependent on an intracellular calcium release; the other probably involves calcium influx and causes only the glycosidase release.

\section{Materials and methods}

\section{Biological materials and chemicals}

Phallusia mammillata was collected intertidally from the Atlantic Ocean at Le Fret or subtidally from the Mediterranean Sea at Sete, France. Eggs and sperm were removed surgically and the sperm stored as dry as possible in the cold and the eggs washed several times in natural sea water (SW).

The calcium-free SW contained $430 \mathrm{mM} \mathrm{NaCl}$, $9 \mathrm{mM} \mathrm{KCl}, 23 \mathrm{mM} \mathrm{MgCl}, 26 \mathrm{mM} \mathrm{MgSO}, 2 \mathrm{mM}$ $\mathrm{NaHCO}_{3}$ or $10 \mathrm{mM}$ Tris $\mathrm{pH}$ 8.2. Ionomycin was prepared as a $1.34 \mathrm{mM}$ stock solution in ethanol and added to a final concentration of $2.7 \mu \mathrm{M}$ to $\mathrm{SW}$ or calcium-free SW. Ryanodine was made as a $20 \mathrm{mM}$ stock in water and diluted to $0.2 \mathrm{mM}$ for use. A $0.1 \mathrm{M}$ stock solution of carbachol was diluted to $2 \mathrm{mM}$ in SW or calcium-free SW for use. Emetine was prepared as a $3 \mathrm{mg} / \mathrm{ml}$ stock solution in water and used at a final concentration of $100 \mu \mathrm{g} / \mathrm{ml}$ in SW. Isoproterenol and acetylcholine were prepared as $5 \mathrm{mM}$ stock solutions in water and diluted to $100 \mu \mathrm{M}$ in SW for use. BAPTA-AM ([bis-(o-aminophenoxy)-ethane$N, N, N^{\prime}, N^{\prime}$-tetraacetic acid, tetra(acetoxymethyl)ester], Molecular Probes, OR) was prepared as a $0.41 \mathrm{mM}$ stock solution in dimethylsulphoxide (DMSO, Sigma) and diluted to $8.2 \mu \mathrm{M}$ in a $3 \mathrm{ml}$ calcium-free SW egg suspension which also contained $20 \mu \mathrm{l}$ DMSO and $40 \mu \mathrm{l}$ of $10 \%$ Pluronics detergent (Marx \& Maxfield, 1990). Following incubation at $23^{\circ} \mathrm{C}$ with gentle rocking for $2 \mathrm{~h}$, the eggs were washed several times with complete SW and activated with ryanodine or ionomycin. Ten minutes later the eggs were pelleted by centrifugation and the $N$-acetylglycosaminidase activity determined as outlined below.

\section{$N$-acetylglucosaminidase assay}

$\mathrm{N}$-acetylglucosaminidase activity was assayed using 4-methylumbelliferyl-GlcNAc (Sigma) as a substrate (Lambert, 1989). To $0.5 \mathrm{ml}$ citrate buffer at $\mathrm{pH} 4.2$ was added $4 \mu \mathrm{l}$ of $25 \mathrm{mM}$ stock solution of the substrate in dimethylformamide, following which was added $200 \mu \mathrm{l}$ of the fertilisation supernatant. After $30 \mathrm{~min}$ at room temperature, $2 \mathrm{ml}$ of $0.1 \mathrm{M}$ sodium carbonate was added and the fluorescence determined in a Hoefer TKO 100 fluorometer at an excitation of $365 \mathrm{~nm}$ and emission at $460 \mathrm{~nm}$.

\section{Microinjection and intracellular calcium measurements}

For microinjection, all oocytes were first dechorionated by placing them for $2 \mathrm{~h}$ at $18-21^{\circ} \mathrm{C}$ in $5 \mathrm{mM}$ TAPS-buffered sea water ( $\mathrm{pH} 8.2$ ) supplemented with $0.1 \%$ trypsin. The trypsin was then removed by 
washing several times in SW (Sardet et al., 1989). The dechorionated oocytes were mounted into a microinjection chamber essentially as described by Kiehart (1982) and Speksnijder at al. (1990). All glass or plastic surfaces which the dechorionated oocytes came into contact with were previously coated with gelatin (0.1\% gelatin/formaldehyde; Sardet et al., 1989). Dextran-coupled (10000 molecular weight) calcium green-1 (calcium sensitive) and texas red (calcium insensitive) (Molecular Probes,OR) were dissolved in injection buffer $(180 \mathrm{mM} \mathrm{KCl}, 30 \mathrm{mM}$ BES ( $N, N$-bis(hydroxyethyl)-2-aminoethanesulphonic acid), $100 \mu \mathrm{M}$ EGTA, pH 7.4) and injected using a high-pressure system (essentially as described in Swann \& Whitaker, 1986) into dechorionated oocytes to give a final intracellular concentration of $10-20 \mu \mathrm{M}$. Glass pipettes (GC 100 F10, Clarke Electrochemical Instruments, Pangbourne, UK) were pulled using a Kopf vertical puller (model 720, David Kopf Instruments, Tajunga, CA).

To image the increase in the $\mathrm{Ca}_{\mathrm{i}}^{2+}$ levels, we used a Leica confocal microscope equipped with a Leitz Fluotar $\times 40 / 1.3$ oil immersion objective lens and an argon-krypton laser, which gives prominent emissions at $488 \mathrm{~nm}$ and $568 \mathrm{~nm}$. We separated the calcium green and texas red fluorescent emission using a $580 \mathrm{~nm}$ dichroic filter. The calcium green fluorescent emission was passed through a $532 \mathrm{~nm}$ bandpass filter and the texas red emission passed through a $590 \mathrm{~nm}$ longpass filter. The emissions were collected by two photomultipliers, one for each emission wavelength, and later divided pixel by pixel to give a ratiometric image in real time (McDougall \& Sardet, 1995).

\section{Results}

\section{Patterns of intracellular calcium release induced by various activators}

Phallusia eggs were co-injected with 10000 molecular weight dextran-coupled calcium green-1 and texas red by high-pressure microinjection and treated with sperm, ionomycin or ryanodine. Although it was difficult to determine the actual time of sperm-egg fusion under our experimental conditions, the first calcium increase always occurred about $30-40 \mathrm{~s}$ before the onset of the first cortical contraction (in Plate $1 a$ (facing p. 00) the egg begins to move by frame 4 because the cortical contraction causes the egg to deform). After the initial $\mathrm{Ca}_{\mathrm{i}}^{2+}$ increase, periodic calcium waves occur at about $2 \mathrm{~min}$ intervals for the next 20-25 min. This confirms the previous observations from aequorininjected eggs (Speksnijder et al., 1989, 1990). Activation by ionomycin leads to a nearly immediate $\mathrm{Ca}_{i}^{2+}$ increase followed by a sustained increase in $\mathrm{Ca}_{\mathrm{i}}^{2+}$.
Again a shape change indicative of the cortical contraction begins about $40 \mathrm{~s}$ after the first $\mathrm{Ca}_{\mathrm{i}}^{2+}$ increase (see frame 3 , Plate $1 b$ ). Ryanodine gave no detectable increase in $\mathrm{Ca}_{\mathrm{i}}^{2+}$ (data not shown).

\section{Time course of the cortical contraction and egg deformation}

Previous studies have determined the time course of cortical contractions by examining single dechorionated eggs in the microscope (Sardet et al., 1989). The problem with this method is that it is nearly impossible to judge the time of sperm-egg fusion unless the increase in the $\mathrm{Ca}_{\mathbf{i}}^{2+}$ level is also monitored. In this study, we fixed aliquots from a single culture of chorionated eggs at various times after addition of sperm and counted the proportion of obviously nonspherical eggs in a simple of 100 (Fig. 1). This analysis yields three major peaks of egg deformation. The first peak of deformation is a consequence of the calciuminduced cortical contraction and movement of the mitochondria-rich domain (the myoplasm) towards the vegetal pole. It is completed about $4-5 \mathrm{~min}$ after insemination. Peaks 2 and 3 indicate the deformation of the egg occurring as the polar bodies are formed about 6 and $19 \mathrm{~min}$ after the initial contraction. This

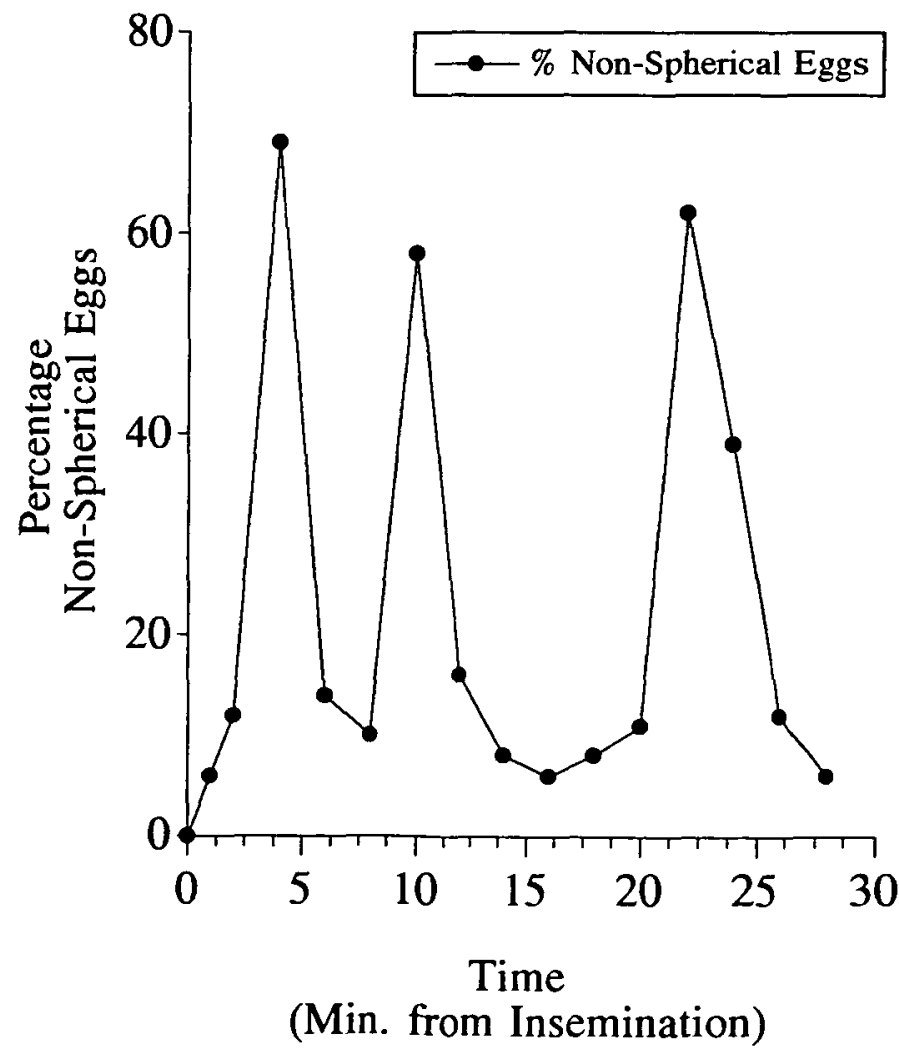

Figure 1 Egg deformation in response to fertilisation. A suspension of eggs was fertilised at time 0 and aliquots fixed at the indicated time points. The percentage of obviously non-spherical eggs at each time point was determined in 100 eggs using differential interference contrast microscopy. 


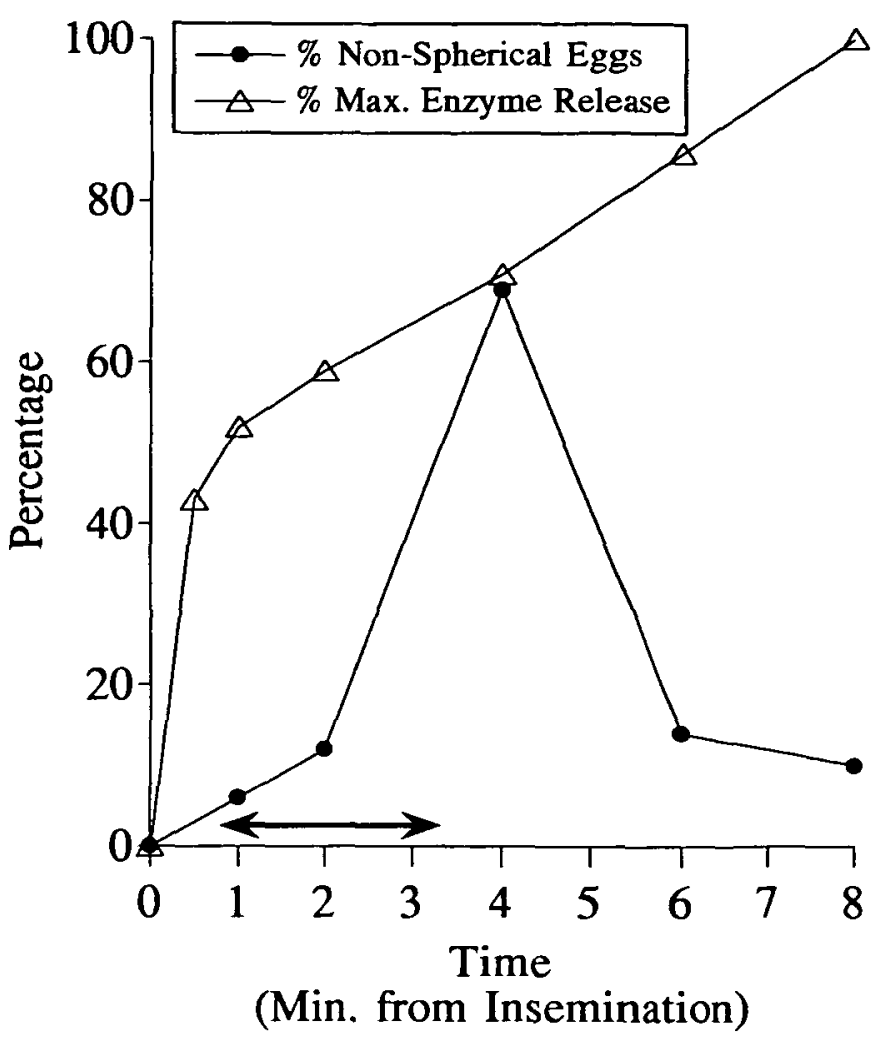

Figure 2 Egg deformation and $N$-acetylglucosaminidase activity released in response to fertilisation. The extent of the cortical contraction was evaluated as in Fig. 1 and glycosidase release determined in supernatant samples withdrawn from the suspension at the indicated times followed by determination of glycosidase activity as described in Methods. The double-headed arrow shows the duration of the first increase in intracellular calcium concentration as determined from experiments shown in Plate 1.

corresponds well to the previous findings on single dechorionated eggs (Sardet et al., 1989).

\section{Rate of cortical contractions and glycosidase release}

We measured glycosidase release by Phallusia eggs by measuring enzyme activity in portions of fertilisation supernatant taken at different times after insemination of a population of eggs (Lambert, 1989). These eggs release large amounts of activity during the first $15 \mathrm{~s}$ and the level continues to increase rapidly during the early phases of fertilisation. This is followed by a steady release occurring at a slower rate after the first minute (Fig. 3). Plotting the rate of glycosidase release and extent of cortical contraction on the same time scale reveals that the bulk of the glycosidase is released well before the first cortical contraction occurs (Fig. 2).

Sperm, ionomycin and emetine all induce cortical contractions, glycosidase release and extrusion of the first polar body. Sperm and ionomycin cause the

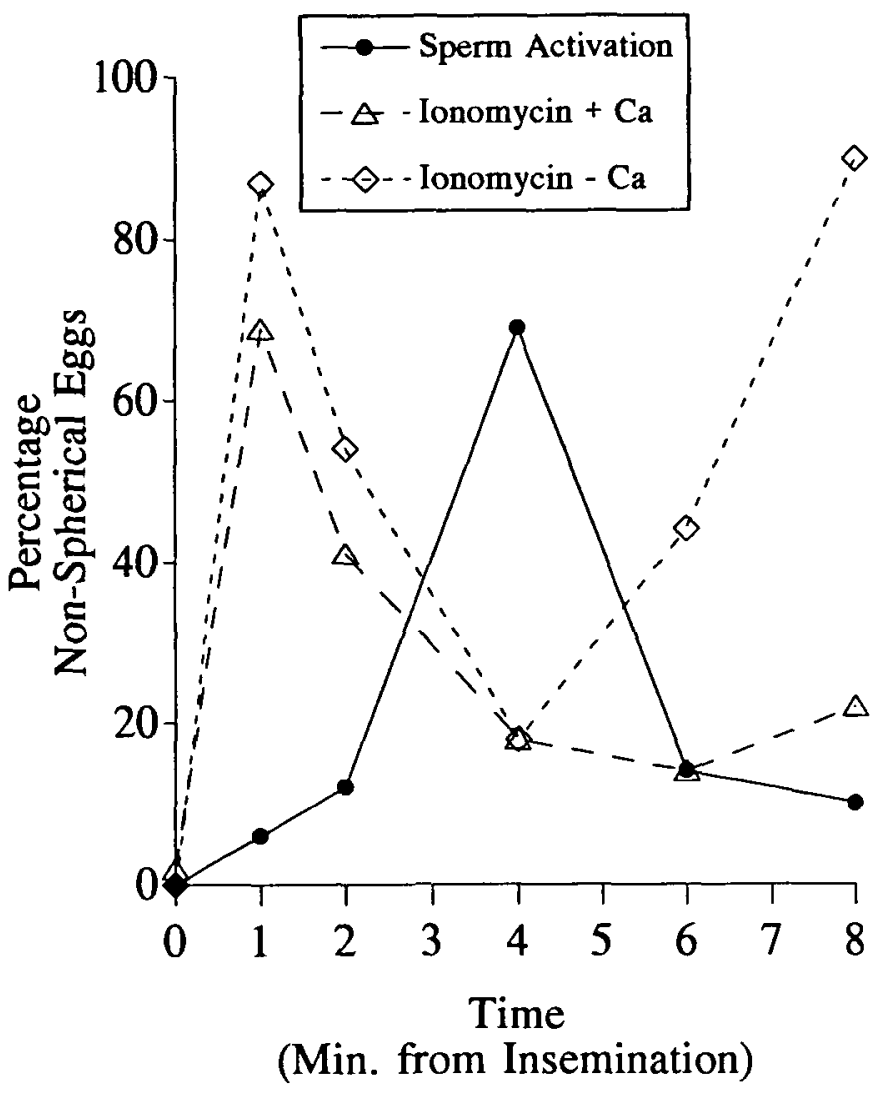

Figure 3 Kinetics of egg deformation induced by sperm or ionomycin in the presence and absence of extracellular calcium. Eggs were fertilised in complete SW or activated with ionomycin $(2.7 \mu \mathrm{M})$. We also activated eggs with ionomycin in calcium-free SW supplemented with $5 \mathrm{mM}$ EGTA. Continuous line and filled circles, complete SW and sperm; dashed line and open triangles, ionomycin in complete SW; dotted line with open diamonds, ionomycin in calcium-free SW containing $5 \mathrm{mM}$ EDTA.

strongest contractions with a peak occurring about 3-4 min after sperm addition and about $1 \mathrm{~min}$ following ionomycin addition (Fig. 3). Cortical contractions induced by ionomycin in the absence of external calcium occur at the same rate as those in the presence of calcium (Fig. 3), thus showing that calcium influx is not an important factor. The cortical contraction and polar body extrusion occur even when 5 mM EGTA in calcium-free sea water is presented extracellularly (to complex all external calcium). Emetine induces a less extreme deformation than sperm or ionomycin. In addition, the first contraction is greatly delayed, taking about $20 \mathrm{~min}$ to complete with emetine (data not shown).

In a previous study, we found that ryanodine would induce glycosidase release but not cortical contractions in sea water (Lambert et al., 1994). The cholinergic agonist acetylcholine and the adrenergic agonist isoproterenol also cause glycosidase release without cortical contractions (Fig. 4). The data in 

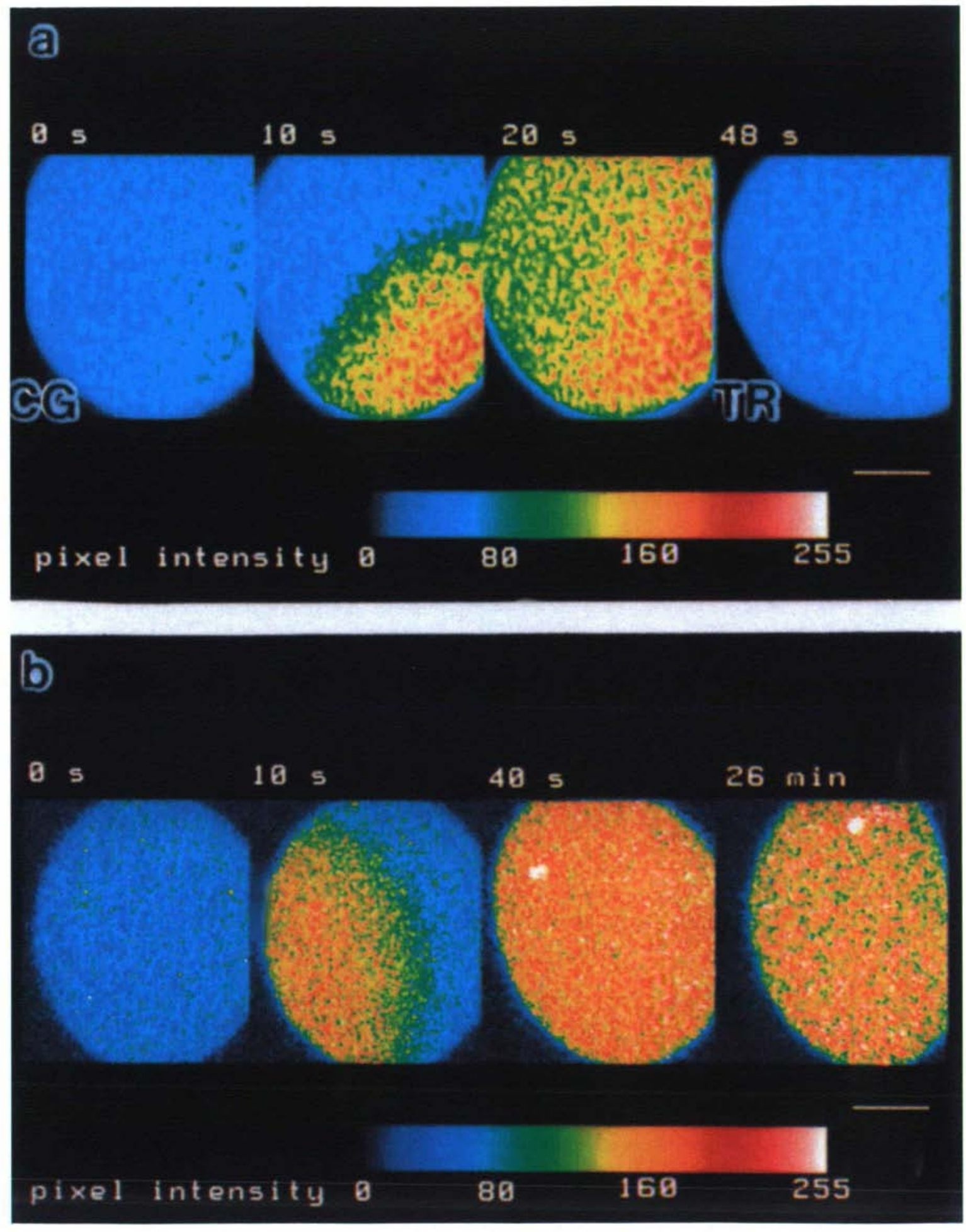

Plate 1. Intracellular calcium concentration increases at fertilisation and following activation by ionomycin. Denuded eggs were microinjected with $10 \mathrm{kDa}$ dextran-coupled calcium green-1 (CG) and texas red (TR) giving an internal concentration of $10-20 \mu \mathrm{M}$ and either fertilised or activated by ionomycin $30 \mathrm{~min}$ after injection. The 1-2 $\mu \mathrm{m}$ thick optical sections were collected using confocal laser scanning microscopy. (a) The first three images (CG) show how the calcium wave passes through the egg cytoplasm, while the last image (TR) shows the cortical contraction beginning in this egg about $40 \mathrm{~s}$ after the calcium wave had begun. (b) Perfusion of $2.7 \mu \mathrm{M}$ ionomycin from the left-hand side induces a comparable increase in intracellular calcium that persists at least for $20 \mathrm{~min}$. The cortical contraction is again induced around $40 \mathrm{~s}$ after the initial calcium increase $(n=6)$. The bars represent $40 \mu \mathrm{m}$. 


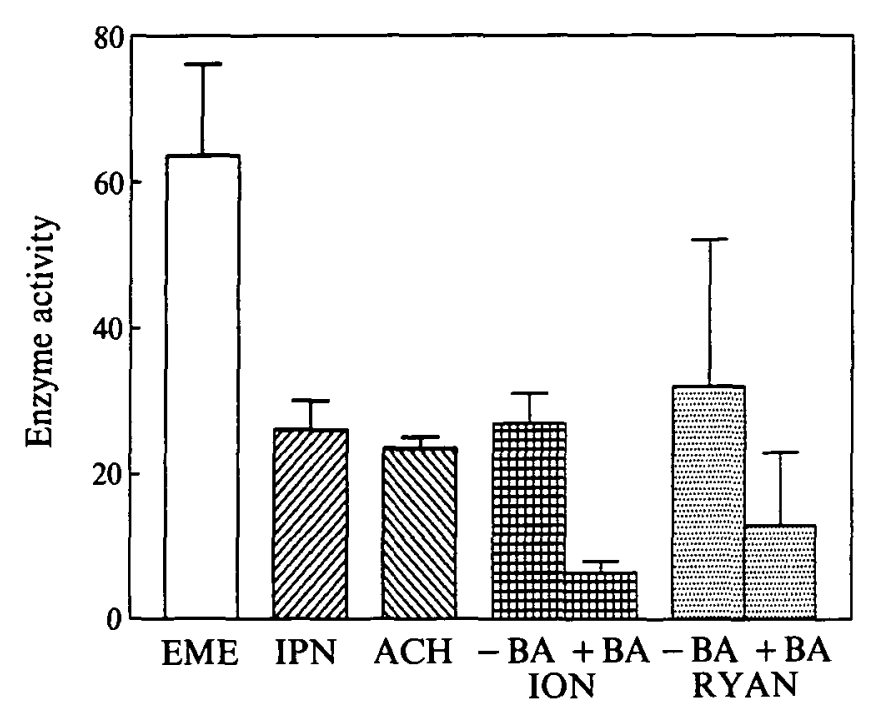

Figure $4 \mathrm{~N}$-acetylglucosaminidase release in responses to emetine, isoproterenol, acetylcholine, ionomycin or ryanodine. Samples from a single batch of eggs were stimulated by $100 \mu \mathrm{g} / \mathrm{ml}$ emetine (EM), $100 \mu \mathrm{M}$ isoproterenol (IPN) or $100 \mu \mathrm{M}$ acetylcholine $(\mathrm{ACH})$ in complete SW. In another experiment we preloaded eggs for $2 \mathrm{~h}$ in calcium-free SW containing $8.2 \mu \mathrm{M}$ BAPTA-AM, 0.1\% Pluronics detergent and $2 \%$ DMSO (+BA). Following this the eggs were washed three times with complete $\mathrm{SW}$ and activated with $2.7 \mu \mathrm{M}$ ionomycin (ION) or $0.2 \mathrm{mM}$ ryanodine (RYAN). Controls were similarly treated but the BAPTA-AM omitted (-BA). Bars show means and standard errors for duplicate determinations. Control levels of glycosidase activity have been subtracted from all values. Supernatant samples were collected $\mathbf{1 0} \mathrm{min}$ after activation and free glycosidase activity determined as in Methods.

Fig. 4 show that ionomycin, like the cholinergic and adrenergic activators, releases roughly similar amounts of glycosidase activity from the egg surface, while emetine (a protein synthesis inhibitor) releases twice as much activity. In this regard, emetine releases as much glycosidase as does treatment with the detergent Triton X-100 (Lambert \& Goode, 1992).

\section{The role of calcium during glycosidase release}

Glycosidase release requires more than trace amounts of calcium in the medium whether the induction is by an agent such as ionomycin, which also causes cortical contractions, or extracellularly applied ryanodine, which never induces the contraction (Lambert et al., 1994). To examine the involvement of an increase in intracellular calcium in glycosidase release, we loaded eggs with the permeant calcium chelator BAPTA-AM. Glycosidase release induced by ryanodine or ionomycin was severely curtailed in BAPTA-loaded eggs (Fig. 4). These findings, together with our previous report (Lambert et al., 1994), show that both glycosidase release and the cortical contraction seem to require an increase in $\mathrm{Ca}_{\mathbf{i}}^{2+}$ levels, and suggest that only glycosidase release depends on calcium influx.

We have previously shown that in eggs of Ascidia ceratodes glycosidase release in response to thapsigargin or ryanodine was inhibited by $10 \mathrm{mM}$ nifedipine, nickel and cobalt (Lambert et al., 1994). Such a high concentration would be expected to block calcium influx through calcium channels by competition, but would not support a model including voltage-gated calcium channels (Hille, 1984). We have now tested for the involvement of voltage-gated calcium channels with selective inhibitors used at more realistic concentrations: verapamil $(200 \mu \mathrm{M})$, methoxyverapamil $(200 \mu \mathrm{M})$, diltiazem $(550 \mu \mathrm{M})$ and pimozide $(55 \mu \mathrm{M})$ (data not shown) all fail to inhibit glycosidase release in response to ryanodine. These studies argue against the involvement of voltage-gated calcium channels during the calcium influx.

\section{Discussion}

\section{Glycosidase release is an early marker of egg activation}

Glycosidase release and cortical contractions are activated by sperm or ionomycin addition to ascidian eggs. With sperm activation, a large part of glycosidase release is achieved within the first minute while the contraction of the egg, which follows the $\mathrm{Ca}_{\mathrm{i}}^{2+}$ increases by some $40 \mathrm{~s}$ (see Plate 1), just begins at this time. Although both processes depend on an $\mathrm{Ca}_{\mathrm{i}}^{2+}$ increase glycosidase release occurs first, probably because it is stimulated by a small non-voltage-gated calcium influx that does not activate the cortical contraction. Thus, the glycosidase release precedes the activation calcium wave which in turn precedes the cortical contraction.

\section{Glycosidase release and calcium}

The information obtained on calcium signals generated at fertilisation using confocal microscopy and calcium-green injected eggs are in good agreement with previous studies using Phallusia eggs injected with aequorin (Speksnijder et al., 1989, 1990). Sperm trigger a large wave of calcium release starting from the point of insemination. The first cortical contraction occurs about $40 \mathrm{~s}$ later. Likewise, ionomycin causes an increase in $\mathrm{Ca}_{\mathbf{i}}^{2+}$ followed by a cortical contraction about $\mathbf{4 0}$ s later (see Plate 1). In contrast to sperm and ionomycin, ryanodine treatment did not trigger any detectable increase in $\mathrm{Ca}_{\mathbf{i}}^{2+}$ levels (monitored with injected calcium green-1 and fluo-3-AM - which has a larger change in fluorescent emission than calcium green-1 between the calcium-free and calcium-bound forms), although we were able to detect, under similar 
experimental conditions, the local rise in cortical calcium induced by depolarisation in sea urchin eggs (McDougal et al., 1993). This failure to detect a ryanodine-induced $\mathrm{Ca}_{\mathbf{i}}^{2+}$ increase is paradoxical since treatment of eggs with the permeable calcium chelator BAPTA-AM inhibits the glycosidase release induced by ryanodine. One possibility is that the calcium increase induced by ryanodine in ascidian eggs is too small and/or localised to be detected by our methods.

We have observed that egg deformation and polar body extrusion occur in the complete absence of external calcium in calcium-free SW supplemented with $5 \mathrm{mM}$ EGTA. This agrees with previous studies (Speksnijder et al., 1989, 1990), but not with a recent paper on activation of Phallusia mammillata eggs (Goudeau \& Goudeau, 1993) which reports that removal of extracellular calcium completely blocks polar body production.

Our studies support the concept that dual calcium controls operate during the activation of the ascidian egg. Activation of the cortical contraction by sperm can be induced by an increase in $\mathrm{Ca}_{\mathrm{i}}^{2+}$ entirely from intracellular stores. This pathway is under $\operatorname{InsP}_{3}$ control and involves large levels of $\mathrm{Ca}_{j}^{2+}$ release from the ER (Speksnijder et al., 1989; McDougall \& Sardet, 1995). Glycosidase release, however, requires extracellular calcium irrespective of the activating agent. Ryanodine, whose only known function is to alter the conductance state of the RYR (often locking the RYR channel open in a sub-conductance state), causes the calcium-dependent glycosidase release without showing a detectable increase in $\mathrm{Ca}_{i}^{2+}$.

\section{Emetine, ryanodine and $G$ protein activators induce glycosidase release}

Our finding that $100 \mu \mathrm{g} / \mathrm{ml}$ emetine induces first polar body formation in Phallusia mammillata eggs confirms and extends the original finding of Abdelmajid et al. (1993). In molluscan eggs, emetine inhibits protein synthesis: this causes a decline in cycline levels inducing the cell to re-enter the cell cycle (Colas et al., 1993). Continued synthesis of some short-lived protein(s) that inhibit cyclin destruction may be necessary to maintain the ascidian egg in first metaphase. The activation calcium wave in ascidians may inactivate the protein synthesis machinery transiently through activation of the committed calmodulin-dependent kinase III that phosphorylates and inactivates elongation factor-Tu (Abdelmajid et al., 1993). At the same time, the activation calcium wave may also increase the activity of the $26 \mathrm{~S}$ proteosome, thus increasing the rate of ubiquitin-tagged protein degradation (Kawahara \& Yokosawa, 1994).

Emetine has other effects on ascidian eggs in addition to inducing clylin destruction, glycosidase release and the cortical contraction. For example, during fertilisation of Ciona intestinalis, the plasma membrane surface area oscillates in phase with the cell cycle (Arnoult et al., 1994). Emetine treatment seems to inhibit the endocytotic phase of this oscillation in surface area; the net result of this is to increase the size of the egg (Arnoult et al., 1994).

Ryanodine, carbachol, isoproterenol and acetylcholine all induce glycosidase release in the presence of extracellular calcium, but they do not induce the cortical contraction. That acetylcholine, carbachol and isoproterenol induce some phases of egg activation demonstrates that ascidian eggs present other similarities to mammalian eggs in addition to the periodic post-activation calcium signals that both display (Miyazaki et al., 1990; Speksnijder et al., 1990; Swann, 1991). Our findings also suggest that ascidian eggs must have both cholinergic and adrenergic receptors on their surface. It is now known whether either receptor is relevant to normal egg activation.

\section{How is the glycosidase released from the plasma membrane?}

The glycosidase is anchored to the outer leaflet of the plasmalemma by means of a phosphatidylinositol linkage and can be released by an exogenous PLC from Bacillus thuringensis. It is likely that a cell surface PLC is involved in freeing the glycosidase from the ascidian egg surface (Lambert \& Goode, 1993), as seems to be the case in several other deuterostome cell types (Dasilva \& Klein, 1989; Ting \& Pogano, 1990, 1991; Volwerk et al., 1992). In ascidian eggs, this pathway is inhibited by BAPTA-AM incubation, requires extracellular calcium and can be blocked by competitive calcium channel blockers (Lambert et al., 1994). Therefore, even though we have been unable to detect a calcium influx using calcium-sensitive dyes, calcium entry seems to be crucial. How is this calcium entry controlled? The lack of inhibition by the four blockers of voltage-gated calcium channels would argue against an activation potential being important for glycosidase release (Hille, 1984). Another possible pathway could involve capacitative calcium entry. In this case, emptying the cortical ER calcium stores may cause release of a low molecular weight phosphorylated molecule that induces opening of non-voltage-gated calcium channels (Putney, 1993, for review). Activation of calcium influx into mouse eggs by thapsigargin has been ascribed to this mechanism (Kline \& Kline, 1992). However, the rapid time course of glycosidase release in response to sperm argues against such a capacitative calcium entry model. One alternative model is that there are $G$ protein modulated calcium channels on the ascidian egg plasma membrane that gate calcium influx and hence trigger glycosidase release. 


\section{Acknowledgements}

For help with collecting Phallusia at Roscoff we thank the laboratory fishermen and T. Honegger. We are indebted to $C$. Rouviere and S. Roger for collecting the Phallusia from Sete. P. Guerrier and L. Meijer have our thanks for many suggestions, reagents and use of their laboratory facilities at Roscoff. We thank Dr H. Yokosawa for sharing his findings with us before publication. The work was supported in part by NSF grant no. DCB-9004735 to C.C.L. and A.M. and ARC grants to C.S. A.M. was supported by EMBO and Royal Society fellowships.

\section{References}

Abdelmajid, H., Leclerc-David, C., Moreau, M., Guerrier, P. \& Ryazanov, A. (1993). Release from the metaphase I block in invertebrate oocytes: possible involvement of $\mathrm{Ca}^{2+}$ calmodulin-dependent kinase III. Int. J. Dev. Biol. 37, 279-90.

Arnoult, C., Georges, D. \& Villaz, M. (1994). Cell cyclerelated fluctuations in oocyte surface area of the ascidian Ciona intestinalis after meiosis resumption. Dev. Biol. 166, 1-10.

Berridge, M.J. (1993). Inositol triphosphate and calcium signaling. Nature 361, 315-25.

Bezprovanny, I., Watras, J. \& Ehrlich, B.E. (1991). Bell-shaped calcium-response curves of $\operatorname{Ins}(1,4,5) \mathrm{P}_{3^{-}}$and calciumgated channels from endoplasmic reticulum of cerebellum. Nature 351, 751-4.

Colas, P., Launay, C., Van Loon, A. \& Guerrier, P. (1993). Protein synthesis controls cyclin stability in metaphase I-arrested oocytes of Patella vulgata. Exp. Cell Res. 208, 518-21.

Dale, B. (1988). Primary and secondary messengers in the activation of ascidian eggs. Exp. Cell Res. 177, 205-11.

Dasilva, A.M. \& Klein, C. (1989). Characterization of a glycosyl-phosphatidylinositol degrading activity in Dicytostelium discoideum membranes. Exp. Cell Res. 185, 464-72.

Galione, A. \& White, A. (1994). $\mathrm{Ca}^{++}$release induced by cyclic ADP-ribose. Trends Cell Biol. 4, 431-6.

Galione, A., McDougall, A., Busa, W.B., Willmott, N., Gilott, I. \& Whitaker, M. (1993). Redundant mechanisms of calcium-induced calcium release underlying calcium waves during fertilization of sea urchin eggs. Science 261, 348-52.

Goudeau, M. \& Goudeau, H. (1993). In the egg of Phallusia mammallata, removal of external calcium modifies fertilization potential, induces polyspermy, and blocks the resumption of meiosis. Dev. Biol. 160, 165-77.

Hille, B. (1984). Ionic Channels of Excitable Membranes. Sunderland: MA: Sinauer Associates.

Kawahara, H. \& Yokosawa, H. (1994). Intracellular calcium calcium mobilization regulates the activity of $26 \mathrm{~S}$ proteosome during the metaphase-anaphase transition in the ascidian cell cycle. Dev. Biol. 166, 623-33,

Kiehart, D.P. (1982). Microinjection of echinoderm eggs. In Methods Cell Biol. 25, 13-31.
Kline, D. \& Kline, J.T. (1992). Thapsigargin activates a calcium influx pathway in the unfertilized mouse egg and suppresses repetitive calcium transients in the fertilized eggs. J. Biol. Chem. 267, 17624-30.

Lambert, C.C. (1989). Ascidian eggs release glycosidase activity which aids in the block against polyspermy. Development 105, 415-20.

Lambert, C.C. \& Goode, C.A. (1992). Glycolipid linkage of a polyspermy blocking glycosidase to the ascidian egg surface. Dev. Biol. 153, 95-100.

Lambert, C.C., Gonzalez, G.P. \& Millar, K.M. (1994). Independent initiation of calcium dependent glycosidase release and cortical contractions during the activation of ascidian eggs, Dev. Growth Differ. 36, 133-9.

Lee, H.C., Aarhus, R. \& Walseth, T.F. (1993). Calcium mobilization by dual receptors during fertilization of sea urchin eggs. Science 261, 352-5.

Marks, P.W. \& Maxfield, F.R. (1990). Transient increases in cytosolic free calcium appear to be required for the migration of adherent human neutrophils. J. Cell Biol. 110, 43-52.

McDougall, A. \& Sardet, C. (1995). Function and characteristics of repetitive calcium waves associated with meiosis. Curr. Biol. 5, 318-28.

McDougall, A.D., Gillot, I. \& Whitaker, M. (1993). Thimerosal reveals calcium-induced calcium release in unfertilised sea urchin eggs. Zygote 1, 35-43.

Miyazaki, S., Katayama, Y. \& Swann, K. (1990). Synergistic activation by serotonin and GTP analogue and inhibition by phorbol ester of cyclic $\mathrm{Ca}^{2+}$ rises in hamster eggs. J. Physiol. (Lond.) 426, 209-27.

Nuccitelli, R. (1991). How do sperm activate eggs? Curr. Top. Dev. Biol. 25, 1-16.

Nuccitelli, R., Yim, D.L. \& Smart, T. (1993). The sperminduced $\mathrm{Ca}^{++}$wave following fertilization in'Xenopus eggs requires the production of $\operatorname{Ins}(1,4,5) \mathrm{P}_{3}$. Dev. Biol. 158, 200-12.

Putney, J.W. (1993). Excitement about calcium signaling in unexcitable cells. Science 262, 676-78.

Sardet, C., Speksnijder, J., Inoué, S. \& Jaffe, L. (1989). Fertilization and ooplasmic movements in the ascidian egg. Development 105, 237-50.

Speksnijder, J., Corson, D.W., Sardet, C. \& Jaffe, L.F. (1989). Free calcium pulses following fertilization in the ascidian egg. Dev. Biol. 135, 182-90.

Speksnijder, J.E., Sardet, C. \& Jaffe, L.F. (1990). The activation wave of calcium in the ascidian egg and its role in ooplasmic segregation. J. Cell Biol. 110, 1589-98.

Swann, K. (1991). Thimerosol causes calcium oscillations and sensitizes calcium-induced calcium release in unfertilized hamster eggs. FEBS Lett. 278, 175-8.

Swann, K. \& Whitaker, M. (1986). The part played by inositol trisphosphate and calcium in the propagation of the fertilization wave in sea urchins. J. Cell Biol. 103, 2333-42.

Swann, K., McDougall, A. \& Whitaker, M. (1994). Calcium signaling at fertilization. J. Mar. Biol. Assoc. U.K. 74, 3-16.

Ting, A.E. \& Pogano, R.E. (1990). Detection of a phosphatidylinositol-specific phospholipase $C$ at the surface of Swiss 3T 3 cells and its potential role in the regulation of cell growth. J. Biol. Chem. 265, 5337-40. 
Ting, A.E. \& Pogano, R.E. (1991). Density dependent inhibition of cell growth is correlated with the activity of a phosphatidyl-inositol specific phospholipase C. Eur. J. Cell Biol. 56, 401-6.

Volwerk, J.J., Birrell, G.B., Hedberg, K.K. \& Griffith, O.H. (1992). A high level of cell-surface phosphatidylinositol- specific phospholipase-C activity is characteristic of growth arrested 3T3 fibroblasts but not of transformed variants. J. Cell. Physiol. 151, 613-22.

Whitaker, M. \& Swann, K. (1993). Lighting the fuse at fertilization. Development 117, 1-12. 